\title{
BMJ Open Inconsistent condom use by male clients during anal intercourse with occasional and regular female sex workers (FSWs): survey findings from southern states of India
}

\author{
Shreena Ramanathan, ${ }^{1}$ Karikalan Nagarajan, ${ }^{2}$ Lakshmi Ramakrishnan, ${ }^{3}$ \\ Mandar K Mainkar, ${ }^{2}$ Prabuddhagopal Goswami, ${ }^{3}$ Diwakar Yadav, ${ }^{3}$ Shrabanti Sen, ${ }^{3}$ \\ Bitra George, ${ }^{3}$ Harikumar Rachakulla, ${ }^{4}$ Thilakavathi Subramanian, ${ }^{5}$ \\ Ramesh S Paranjape ${ }^{2}$
}

To cite: Ramanathan $\mathrm{S}$, Nagarajan K,

Ramakrishnan L, et al. Inconsistent condom use by male clients during anal intercourse with occasional and regular female sex workers (FSWs): survey findings from southern states of India. BMJ Open 2014;4: e005166. doi:10.1136/ bmjopen-2014-005166

- Prepublication history for this paper is available online. To view these files please visit the journal online (http://dx.doi.org/10.1136/ bmjopen-2014-005166).

Received 1 March 2014 Revised 14 October 2014 Accepted 15 October 2014

CrossMark

For numbered affiliations see end of article.

Correspondence to Shreena Ramanathan; sramanathan@fhi360.org

\section{ABSTRACT}

Objectives: Self-reported anal intercourse by female sex workers (FSWs) documented in recent studies from India range between $11.9 \%$ and $22 \%$. However, comparable data on anal intercourse and condom use from male clients of FSWs is lacking. Using data from a bio-behavioural survey (2009-2010), we examined prevalence of anal intercourse, male clients' self-reported inconsistent condom use during anal intercourse with FSWs, and correlates of this behaviour in India's high HIV prevalence southern states (Andhra Pradesh, Maharashtra and Tamil Nadu combined).

Methods: Using two-stage time location cluster sampling, we recruited 4803 clients of FSWs, ages 18-60 years, who had purchased sex from an FSW in the past month. After obtaining informed consent, respondents were interviewed and tested for HIV and sexually transmitted infections (syphilis, gonorrhoea and chlamydia). Logistic regression analysis was used to identify the factors associated with inconsistent condom use during anal intercourse (in the past 6 months) with FSWs.

Results: Overall, $12.3 \%$ clients reported anal intercourse in the past 6 months, of whom $48.4 \%$ used condoms inconsistently. Clients of FSWs who were ages 26 years or older (AOR 2.68, $p=0.032$ ); employed as manual labourers (AOR 2.43, $p=0.013$ ); consumed alcohol (AOR 2.63, $p=0.001$ ); reported five or more sex acts with FSWs in the past month (AOR 2.53, $p=0.031$ ); and perceived themselves to be at higher risk for HIV (AOR 4.82, $p=0.001$ ) were more likely to inconsistently use condoms during anal intercourse.

Conclusions: The results suggest that sex workers and their clients commonly practice anal intercourse, but a relatively high proportion of clients do not consistently use condoms, leading to a greater risk of acquiring HIV and its further transmission to other male and female sexual partners. Given the multidirectional risk, safer sex communication on heterosexual anal intercourse must be incorporated into HIV prevention programmes.
Strengths and limitations of this study

- Using data from a large scale multisite biobehavioural survey, this paper discusses the prevalence and practice of unprotected anal intercourse among clients of sex workers in high HIV prevalent southern states of India.

- Anal intercourse and condom use are both selfreported measures and may therefore be influenced by the social desirability bias, resulting in underreporting or over-reporting of the phenomena.

- There is paucity of behavioral research on clients self-reported anal sex and condom use and this paper examines this relatively understudied risk behaviour.

\section{INTRODUCTION}

Heterosexual anal intercourse (HAI) is an understudied risk behaviour among clients of female sex workers (CFSWs), a vulnerable population that has been identified as a critical bridge group in HIV transmission. ${ }^{12}$ HAI has thus far received little attention, even though depictions of heterosexual anal intercourse can be found in art and artefacts dating to antiquity. ${ }^{3}$ The silence on this front is perhaps linked to society's discomfort with HAI, coupled with the notion that anal intercourse is a homosexual male practice, not heterosexual. ${ }^{3}{ }^{4}$ Most HIV transmission in India occurs through heterosexual networks ${ }^{5}$ and unprotected, heterosexual transactional sex plays a central role in the spread of HIV. ${ }^{7}$ Previous studies indicate that condom usage is higher for vaginal intercourse than for heterosexual anal sex. ${ }^{8}{ }^{9}$ Furthermore, studies have documented condom breakage when condoms were used during anal intercourse, thereby 
increasing chances of infection. ${ }^{10-12}$ While behavioural interventions targeting FSWs have substantially reduced HIV prevalence in general, the FSWs' HIV and STI vulnerability remains high due to the increasing trend of risky behaviours, such as unprotected anal intercourse with clients. $^{13} 14$

Given the high vulnerabilities associated with HAI in commercial and non-commercial sex settings, a few research studies have assessed anal intercourse prevalence and associated factors among FSWs and the general population. ${ }^{15-17}$ Similar to findings from other countries in commercial sex settings, studies on FSWs in India have also documented an increased trend for anal intercourse with clients. ${ }^{13} 141819$ In India and elsewhere, the primary reason for FSWs selling anal sex is the extra money it brings from clients. It is also linked to associated factors such as economic hardship, debt status and lack of alternate source of income. ${ }^{14} 18$ Anal intercourse is usually demand driven, not preferred by FSWs and at times even forced by clients through violence. ${ }^{15} 182021$ Intervention and research in the area are extensive among FSWs. However, there is paucity of behavioural research on clients' self-reported anal intercourse and condom use during anal intercourse. This paper examines the correlates of clients' inconsistent condom use during anal intercourse with FSWs. The study has used cross-sectional survey data collected from clients of FSWs in three high-HIV prevalence states of India.

\section{MATERIALS AND METHODS \\ Data source}

Data were derived from a cross-sectional bio-behavioural survey (called integrated behavioural and biological assessment (IBBA)) that was conducted among clients of FSWs as part of the evaluation of a large-scale HIV prevention programme in 12 districts across the three Indian states of Andhra Pradesh, Maharashtra and Tamil Nadu during 2009-2010. Men, of ages 18-60 years, who reported purchasing sex from an FSW in the past month, were considered eligible respondents. These eligible respondents were identified with the help of FSWs, brokers, pimps, etc, at places of FSW solicitation/entertainment and recruited for the study. The survey used a two-stage cluster sampling design with time location clusters as primary sampling units. Clusters were randomly selected by using probability proportional to size in the first stage. From these selected clusters, respondents were then selected through systematic random sampling in the second stage. Behavioural information was collected through a structured, interviewer-administered questionnaire and blood and urine samples were collected to test for HIV and other sexually transmitted infections (STIs, gonorrhoea, chlamydia, syphilis). A detailed description of the survey methodology is available elsewhere. ${ }^{22}$

Prior oral or written informed consent was obtained from all respondents.

\section{Conceptual framework}

For the current analysis, a conceptual framework (figure 1, illustrated below) was used as a device to explain and identify the different factors that may be associated with inconsistent condom use during anal intercourse with FSWs.

Inconsistent condom use during anal intercourse was the dependent variable. The independent variables were selected based on their contextual relation with the dependent variable. Based on prior research, individual factors such as risk perception, alcohol use ${ }^{23-25}$ frequency of commercial sex, volume of sex acts, ${ }^{14}{ }^{26}$ having male/ transgender partners, ${ }^{27}$ place of soliciting $\mathrm{FSWs}^{5}$ and having HIV/STIs, ${ }^{18}$ which are widely seen to influence condom use among different high-risk population groups, were included. We hypothesised that clients who were married, consumed alcohol, solicited FSWs from public places and had a higher number of FSW partners were more likely to be inconsistent condom users. These clients were also more likely to have experienced anal sex with a man. Most current interventions for clients of FSWs are limited to condom promotion and distribution, and no

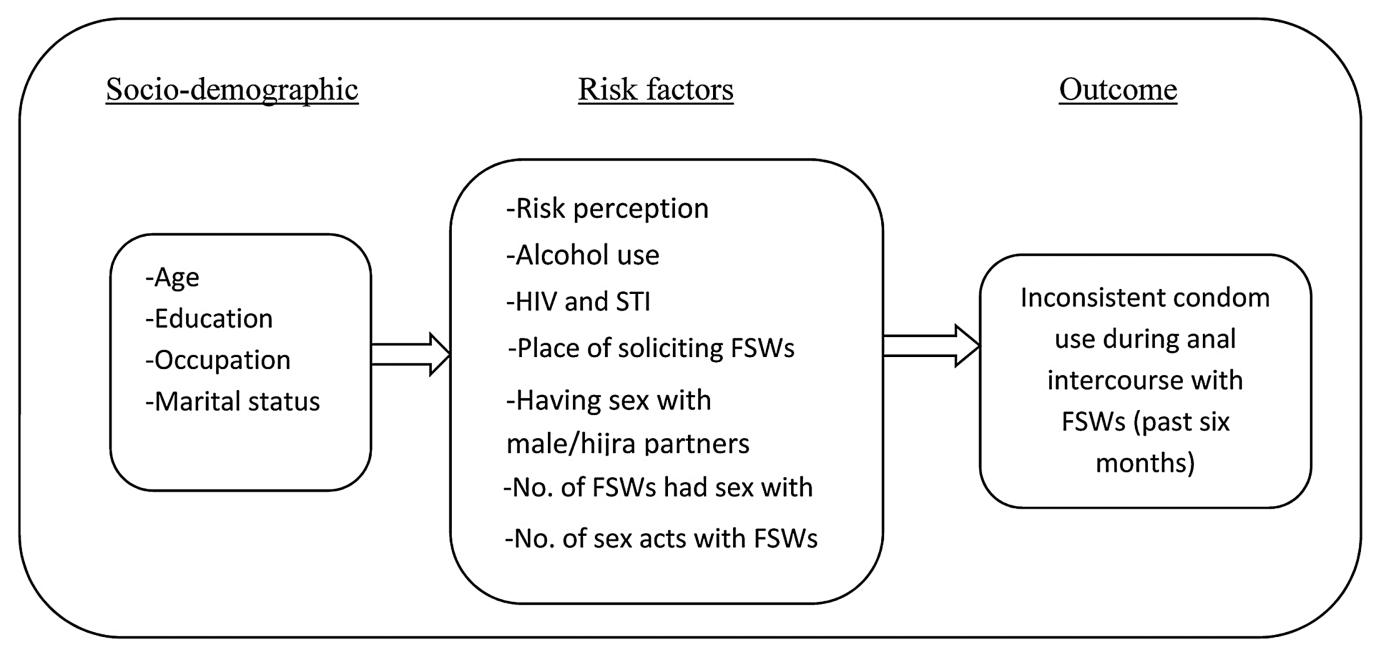

Figure 1 Conceptual framework of factors related with inconsistent condom use during anal intercourse. 
intervention for FSWs or their clients currently addresses heterosexual anal intercourse, which has significant implications for HIV prevention programming.

Based on the rationale described above, we grouped the different indicators into two categories: (1) sociodemographic and (2) HIV-related sexual risk behaviours.

\section{Measures}

Dependent variable

Inconsistent condom use during anal intercourse-This behaviour was assessed by asking: "How often did you use a condom while having anal intercourse with your regular and occasional FSWs in the past six months?" The clients who reported using condoms most of the time, sometimes or never were considered inconsistent condom users (coded as ' 1 '), while those who reported using condoms every time during anal intercourse were considered consistent condom users (coded as ' 0 ').

\section{Independent variables}

The independent variables included age in completed years; education (illiterate, can read only, can read and write); occupation (pre-coded as unemployed, student, domestic servant, agricultural labour, non-agricultural/ casual labour, skilled/semiskilled labour, petty businessman/shop owner, large businessman/shop owner, bus/ truck driver/helper, other transport worker, service and others); marital status (currently married, separated, divorced, widowed, never married, no answer); place of soliciting FSWs (pre-coded as bar/nightclub, public place, street, park, railway station, agent, brothel, hotel/ lodge, home, dhaba, by telephone, other); number of FSWs they had sex with in the past month; number of sex acts with FSWs in the past month; ever had anal intercourse with a man/transgender (yes/no); self-risk perception (yes/no); alcohol consumption (every day, at least once a week, less than once a week, never, no answer); and having HIV or any STI (those having HIV, syphilis, gonorrhoea or chlamydia were grouped into positive and the rest as negative).

Given the skewed distribution, all the variables were dichotomised for the analysis. Age was categorised into $\leq 25$ years and 26 years or older; education was grouped into literate and illiterate; occupation into labourers (manual) and non-labourers, marital status as currently married and never married, widowed/separated/divorced; place of soliciting FSWs into public place and non-public place; number of FSWs had sex with as $\leq 3$ FSWs and $\geq 4$ FSWs; number of sex acts as $\leq 4$ times and $\geq 5$ times; and alcohol use into frequent and infrequent drinkers.

\section{Statistical analysis}

Descriptive statistics were calculated and used to measure the levels of inconsistent condom use (during anal intercourse) and other selected variables. $\chi^{2}$ Tests were used to assess the significance of bivariate relationships between demographic characteristics of clients and their condom use behaviour during anal intercourse.
Multiple logistic regression model was used to identify factors that were independently predictive of inconsistent condom use during anal intercourse, with adjusted OR calculated at a significance level of less than 0.05 . Statistical calculations were conducted using aggregated data of clients of FSWs from all three states, since the eligibility critieria for respondents and the methods of sampling and behavioural data collection were standardised and the same in all the three states. Analysis was performed by applying appropriate weights. At the district level, weighting was based on the cluster effect of the sample. At the aggregate level, standardised weights were calculated by combining the 12 districts. STATA/SE V.11 (Stata Corporation, College Station, Texas, USA) was used for all the analyses.

\section{RESULTS}

Of the 4803 clients of FSWs (Andhra Pradesh $(n=2016)$, Tamil Nadu ( $n=1217)$ and Maharashtra $(n=1570), 12.3 \%$ reported having had anal intercourse in the past 6 months; $48.4 \%$ among them used condoms inconsistently during anal intercourse. In Andhra Pradesh, Maharashtra and Tamil Nadu those reporting anal sex were $18.9 \%, 6.5 \%$ and $17.7 \%$, respectively. Condom use during anal and vaginal sex varied widely in the different states (figure 2) and since only a small proportion of clients in each of these states reported anal sex, the findings are based on an aggregate analysis.

As presented in table 1, the bivariate analysis shows that the majority of inconsistent condom users were ages 26 years or older $(84.3 \%)$, married $(79.8 \%)$ and solicited FSWs from public places $(77.1 \%)$. Literacy levels were lower among inconsistent condom users than among consistent condom users $(50 \%$ vs $85.2 \%$, $\mathrm{p}=0.003$ ). Similarly, a lower proportion of inconsistent condom users reported having had anal intercourse with a man than consistent condom users $(18.7 \%$ vs $39.4 \%$, $\mathrm{p}=0.022)$. A higher proportion of inconsistent condom users consumed alcohol frequently $(56 \%$ vs $37.5 \%$, $\mathrm{p}=0.031)$ and considered themselves at risk of exposure to HIV than consistent condom users $(47.9 \%$ vs $7.13 \%$, $\mathrm{p}=0.000$ ). More than $30 \%$ inconsistent condom users tested positive for HIV/STI, compared to a smaller proportion of consistent condom users $(32.3 \%$ vs $9.7 \%$, $\mathrm{p}=0.085$ ), but the association is not significant.

Table 2 shows the independent factors associated with inconsistent condom use during anal intercourse with FSWs. Clients of FSWs who were ages 26 years or older (AOR 2.68, $\mathrm{p}=0.032$ ), employed as manual labourers (AOR 2.43, $\mathrm{p}=0.013$ ), consumed alcohol (AOR 2.63, $\mathrm{p}=0.001$ ), reported five or more sex acts with FSWs in the past month (AOR 2.53, p=0.031) and perceived themselves to be at higher risk for HIV (AOR 4.82, $\mathrm{p}=0.001$ ) were more likely to inconsistently use condoms during anal intercourse than their counterparts. On the other hand, clients who were currently married (AOR $0.41, \mathrm{p}=0.056$ ) and had sex with a higher number of 


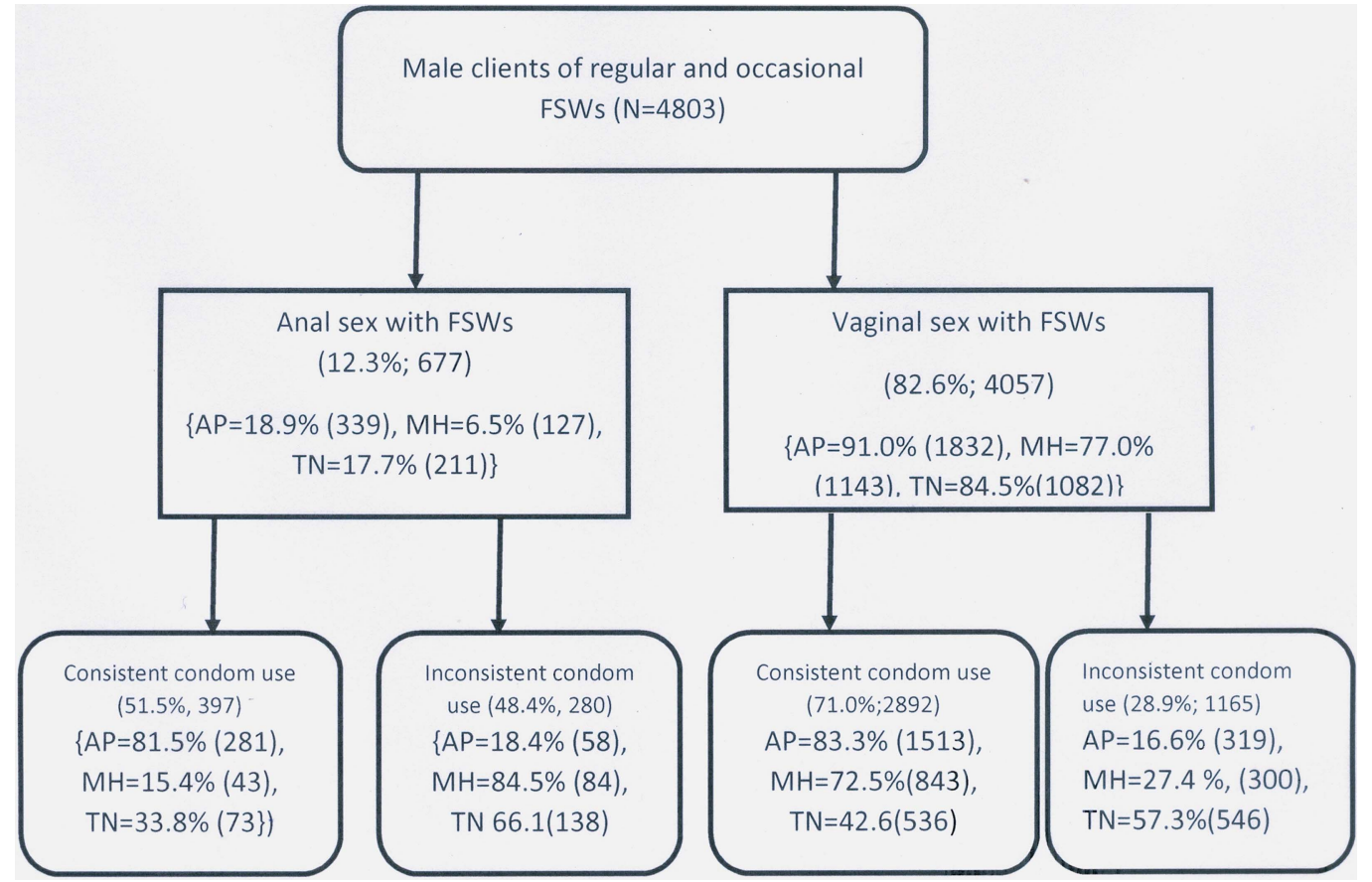

Figure 2 Proportions of reported anal-vaginal sex and consistent condom use among male clients of regular and occasional female sex workers in Andhra Pradesh (AP), Maharashtra (MH) and Tamil Nadu (TN).

FSWs ( $\geq 4$ and above) in the past month were less likely to inconsistently use condoms during anal intercourse than those who never married or were separated/ divorced/widowed and who had sex with less than three FSWs. Testing positive for HIV or STI was not found to be associated with inconsistency in condom use during anal intercourse. Similarly, factors such as literacy level, place where the client solicited FSWs and whether he had had anal sex with a male/hijra partner were not associated with inconsistency in condom use during anal intercourse.

\section{DISCUSSION}

IBBA, one of the few surveys in India to study large samples of clients of FSWs, has documented the practise of unprotected anal intercourse in three high HIV prevalence states of the country. Its findings show that anal intercourse is a substantial part of commercial sex activity in India, with about $12 \%$ of clients reporting experience of anal intercourse and nearly half of them not using condoms during anal intercourse with FSWs. The profile of clients who reported having unprotected anal intercourse with FSWs varied from clients who did not report unprotected sex. Clients who were 26 years or older, frequently used alcohol, worked as manual labourers and reported a higher number of sex acts with FSWs were at an increased risk of unprotected anal intercourse.

In the absence of comparable estimates on anal intercourse from client surveys in India, we examined the estimates available from studies on FSWs ${ }^{13} 141828$ and the reported prevalence ranged from $11.9 \%$ to $22 \%$.
It was apparent from these studies that there is a high demand for anal sex from male clients of FSWs (above $40 \%$ ). When compared with the prevalence reported by FSWs in these studies, the prevalence reported by clients in the current analysis is comparable and an almost similar prevalence was reported by FSWs in round one of IBBA. ${ }^{28}$ Anal sex is certainly stigmatised among FSWs and they have a reason to under-report this behaviour, however, we do not know if it is similar for men.

The finding that older clients are at a higher risk of inconsistent condom use has been reported previously. Inconsistent condom use during vaginal intercourse with FSWs was found to be significantly associated with older clients. ${ }^{2}$ The average age of marriage for Indian men is documented to be 26 years, and a majority of men (clients of FSWs) in this sample were married. A possible explanation for this risky behaviour among older men could be the need to fulfil sexual desires or experimentation, followed by the belief that paying for sex would be less troublesome and more entertaining than sexual involvement with a non-sex worker. ${ }^{29}$ It could also be plausible that inability of the older men to maintain erections may have resulted in inconsistent use of condoms during anal sex when compared to younger men. Older men who have sex with men have also been found to practice risky sexual behaviour such as inconsistent condom use. ${ }^{30}$

Likewise, clients who were manual labourers were more likely to be inconsistent condom users, compared to those in other occupations (white collar workers). The manual labourers in the current study include agricultural and non-agricultural labourers and cultivators. 
Table 1 Characteristics of clients of FSWs who reported anal intercourse (past 6 months) with occasional and regular FSWs and condom use

\begin{tabular}{|c|c|c|c|}
\hline Characteristics & $\begin{array}{l}\text { Consistent condom users } \\
(\mathrm{n}=397, \mathbf{5 1 . 5 \%} \% \text { (number) }\end{array}$ & $\begin{array}{l}\text { Inconsistent condom users } \\
\text { ( } \mathrm{n}=\mathbf{2 8 0}, \mathbf{4 8 . 4 \% )} \% \text { (number) }\end{array}$ & p-Value \\
\hline \multicolumn{4}{|l|}{ Age } \\
\hline$\leq 25$ years & $27.1(117)$ & $15.6(53)$ & \multirow[t]{2}{*}{0.165} \\
\hline 26 years or older & $72.8(280)$ & $84.3(227)$ & \\
\hline \multicolumn{4}{|l|}{ Education } \\
\hline Illiterate & $14.8(64)$ & $49.9(57)$ & \multirow[t]{2}{*}{0.003} \\
\hline Literate & $85.2(333)$ & $50.0(223)$ & \\
\hline \multicolumn{4}{|l|}{ Marital status } \\
\hline Never married/widowed/separated/divorced & $29.8(120)$ & $20.11(84)$ & \multirow[t]{2}{*}{0.266} \\
\hline Currently married & $70.1(277)$ & $79.8(196)$ & \\
\hline \multicolumn{4}{|l|}{ Occupation } \\
\hline Non-labourer (students/business/service) & $51.4(214)$ & $46.1(90)$ & \multirow[t]{2}{*}{0.749} \\
\hline $\begin{array}{l}\text { Manual labourer (agricultural/non-agricultural } \\
\text { labour/cultivator) }\end{array}$ & $48.5(181)$ & $53.8(190)$ & \\
\hline \multicolumn{4}{|l|}{ Place solicited FSWs } \\
\hline Non-public place (brothel/home/lodge/dhaba) & $30.6(117)$ & $22.9(93)$ & \multirow[t]{2}{*}{0.448} \\
\hline Public place & $69.3(278)$ & $77.1(186)$ & \\
\hline \multicolumn{4}{|l|}{ Number of FSWs had sex with in the past 1 month } \\
\hline$\leq 3$ FSWs & $72.3(324)$ & 86.4 (229) & \multirow{2}{*}{0.088} \\
\hline$\geq 4 \mathrm{FSWs}$ and above & $27.6(73)$ & $13.5(51)$ & \\
\hline \multicolumn{4}{|l|}{ Number of sex acts with FSWs in the past 1 month } \\
\hline$\leq 4$ times & $73.7(285)$ & $76.0(184)$ & \multirow[t]{2}{*}{0.812} \\
\hline$\geq 5$ and above & $26.2(111)$ & $23.9(95)$ & \\
\hline \multicolumn{4}{|l|}{ Perceive to be at high risk of exposure to HIV } \\
\hline No & $92.8(337)$ & $52.0(188)$ & \multirow[t]{2}{*}{0.000} \\
\hline Yes & $7.13(39)$ & $47.9(82)$ & \\
\hline \multicolumn{4}{|l|}{ Alcohol user } \\
\hline Infrequent drinker & $62.4(262)$ & $43.9(142)$ & \multirow[t]{2}{*}{0.031} \\
\hline Frequent drinker (every dav) & $37.5(116)$ & $56.0(121)$ & \\
\hline \multicolumn{4}{|l|}{ Ever had anal intercourse with a man/hijra } \\
\hline No & $60.5(311)$ & $81.2(179)$ & \multirow[t]{2}{*}{0.022} \\
\hline Yes & $39.4(86)$ & $18.7(101)$ & \\
\hline \multicolumn{4}{|l|}{ Any HIV/STIs } \\
\hline Negative & $90.2(367)$ & $67.6(253)$ & \multirow[t]{2}{*}{0.085} \\
\hline Positive & $9.7(30)$ & $32.3(27)$ & \\
\hline
\end{tabular}

It is possible that many of these men migrated for work and stay away from their families. Additional analysis was undertaken to understand this dimension better; more than $50 \%$ respondents reported travelling in the past 1 year, primarily for work. These men also reported buying sex from FSWs. Given this scenario, it is imperative that tailored interventions be designed for those involved in manual labour, who are often difficult to engage in prevention programmes. These men could be captured through networks of labour contractors and migrant populations. Educational campaigns and counselling are also important to promote condom use for all partners and all types of sex.

Our study also found that clients with higher selfperceived risk for HIV were more likely to be inconsistent condom users. Such an association could be attributed to the fact that knowledge and perceptions about safe or risky sex may not be sufficient to change an individual's behaviour until self-efficacy and determination in executing a behaviour or action are present. ${ }^{31}$ Studies that have used the self-efficacy model among heterosexually active students have documented that risk perceptions have no influence over condom use, as was noted in this study. ${ }^{8}{ }^{32}$ Another plausible reason could be the lack of targeted interventions for clients, which, if present, could have inculcated a sense of responsibility toward their sexual partners.

Men who consume alcohol have been found more likely to engage in unprotected sex and anal sex and have more than 10 FSW partners. ${ }^{33}$ A similar association was observed in our study, where clients who consumed alcohol frequently and reported five or more sexual encounters were found to inconsistently use condoms during anal intercourse. It appears that the survey has been able to capture high-risk clients who have a higher volume of sex acts with FSWs, engage in anal intercourse and do not use condoms. Alcohol use and its association with HIV-related sexual risk is well documented. ${ }^{33-35}$ HIV prevention 
Table 2 Independent factors associated with inconsistent condom use during anal intercourse with FSWs in multivariate analysis

\begin{tabular}{|c|c|c|c|c|}
\hline Characteristics & Crude OR $(95 \% \mathrm{Cl})$ & p Value & Adjusted OR (95\% Cl) & p Value \\
\hline \multicolumn{5}{|l|}{ Age } \\
\hline$\leq 25$ years & Referent & & Referent & \\
\hline 26 years or older & $2.00(0.74$ to 5.40$)$ & 0.170 & 2.68 (1.09 to 6.61$)$ & 0.032 \\
\hline \multicolumn{5}{|l|}{ Education } \\
\hline Illiterate & Referent & & Referent & \\
\hline Literate & $0.17(0.05$ to 0.59$)$ & 0.005 & $0.66(0.28$ to 1.56$)$ & 0.347 \\
\hline \multicolumn{5}{|l|}{ Occupation } \\
\hline Non-labourer (student/business/service) & Referent & & Referent & \\
\hline $\begin{array}{l}\text { Manual labourer (agricultural/non-agricultural } \\
\text { labour/cultivator) }\end{array}$ & $1.23(0.33$ to 4.48$)$ & 0.749 & $2.43(1.21$ to 4.90$)$ & 0.013 \\
\hline \multicolumn{5}{|l|}{ Marital status } \\
\hline Never married or widowed/separated/divorced & Referent & & Referent & \\
\hline Currently married & $1.69(0.66$ to 4.31$)$ & 0.269 & $0.32(0.13$ to 0.80$)$ & 0.015 \\
\hline \multicolumn{5}{|l|}{ Place solicited FSWs } \\
\hline Non-public place (brothel/home/lodge/dhaba) & Referent & & Referent & \\
\hline Public place & $1.49(0.52$ to 4.20$)$ & 0.449 & $1.26(0.60$ to 2.61$)$ & 0.533 \\
\hline \multicolumn{5}{|c|}{ Number of FSWs had sex with in the past 1 month } \\
\hline$\leq 3 \mathrm{FSWs}$ & Referent & & Referent & \\
\hline$\geq 4$ FSWs and above & $0.41(0.14$ to 1.16$)$ & 0.094 & $0.29(0.10$ to 0.84$)$ & 0.022 \\
\hline \multicolumn{5}{|l|}{ Number of sex acts with FSWs in the past 1 month } \\
\hline$\leq 4$ times & Referent & & Referent & \\
\hline$\geq 5$ and above & $0.88(0.32$ to 2.41$)$ & 0.812 & $2.53(0.09$ to 5.90$)$ & 0.031 \\
\hline \multicolumn{5}{|l|}{ Perceive self to be at high risk of exposure to HIV } \\
\hline No & Referent & & Referent & \\
\hline Yes & 11.99 (3.08 to 46.5$)$ & 0.000 & $4.82(1.91$ to 12.14$)$ & 0.001 \\
\hline \multicolumn{5}{|l|}{ Alcohol user } \\
\hline Infrequent drinker & Referent & & Referent & \\
\hline Frequent drinker (every day) & 2.11 (1.06 to 4.20$)$ & 0.033 & 2.63 (1.46 to 4.71$)$ & 0.001 \\
\hline \multicolumn{5}{|l|}{ Ever had anal intercourse with a man/hijra } \\
\hline No & Referent & & Referent & \\
\hline Yes & 0.35 (0.14 to 0.87$)$ & 0.025 & $0.76(0.39$ to 1.50$)$ & 0.440 \\
\hline \multicolumn{5}{|l|}{ Any HIV/STIs } \\
\hline Negative & Referent & & Referent & \\
\hline Positive & 4.42 (0.74 to 26.32$)$ & 0.102 & 0.73 (0.25 to 2.12$)$ & 0.568 \\
\hline
\end{tabular}

interventions must address this important issue linked with compromise in safe sex practices/behaviour. There is a clear need for HIV prevention interventions tailored to provide information on alcohol-related sexual risk.

Although studies from the early 1990s have highlighted anal intercourse as a risk factor for HIV, ${ }^{96}$ most AIDS prevention messages targeting heterosexuals continue to focus only on vaginal and oral sex transmission. Cultural taboos have possibly played a major role against acknowledging anal sexual practice. Research on vulnerable populations, including FSWs and youth, indicates that those particularly at risk of being infected by or transmitting HIV are more likely to practice anal intercourse. ${ }^{37}$ Furthermore, people with experience in anal intercourse have been found to take more sexual risk when engaging in vaginal intercourse than those without anal experience. ${ }^{8}$ Another important aspect is the condom negotiating ability of sex workers with clients. Factors in the physical, economic and policy environment influence condom use. In addition, the gendered power dynamics and the lack of choice sex workers have with heterosexual anal intercourse exacerbates their vulnerability. Sex workers need to be empowered to negotiate condom use with clients and motivate unwilling clients to use condoms during anal/vaginal sex. ${ }^{38}$

\section{LIMITATIONS OF THE STUDY}

Our study has its limitations. For one, anal intercourse and condom use are both self-reported measures and may, therefore, be influenced by the social desirability bias. As indicated by previous research, the social desirability bias gives rise to the possibility of under-reporting. Given the difficulty in evaluating the magnitude of under-reporting, we must be cautious in concluding that anal intercourse is practiced at relatively low rates among this population. Further, we did not have information on anal intercourse with regular female partners to establish 
concurrency or multidirectional risk during anal intercourse. Also, the survey did not gather information on violence/coercion during anal sex. Future studies are needed to address these gaps. In addition, qualitative studies are needed to better understand the context in which anal intercourse occurs. In spite of these limitations, this is one of the first studies to document for the clients of FSWs the practice of anal intercourse and the correlates of condom use during anal intercourse.

\section{CONCLUSIONS}

The study indicates that HIV prevention programmes targeting FSWs and their clients must highlight the increased risk unprotected anal intercourse poses for self as well as partners. Condoms and water-based lubricants need to be marketed to reduce these risks. Interventions also need to address factors that influence condom negotiation ability of sex workers. Given the multidirectional risk, condom promotion programmes must be extended to include specific information on the benefits of consistent condom use while engaging in anal and other types of sex. Safer sex messages addressing heterosexual anal intercourse need to be incorporated into HIV prevention interventions for FSWs and their clients. Current prevention programmes fail to address this issue. Greater emphasis in AIDS/STI prevention must be given to this typically stigmatised and under-reported sexual practice.

\section{Author affiliations}

${ }^{1}$ Department of M\&E, Knowledge Network, DAKSH, FHI 360, New Delhi, India

${ }^{2}$ National AIDS Research Institute (NARI), Pune, Maharashtra, India

${ }^{3} \mathrm{FHI} 360$, New Delhi, India

${ }^{4}$ National Institute of Nutrition (NIN), Hyderabad, Andhra Pradesh, India

${ }^{5}$ National Institute of Epidemiology (NIE), Chennai, Tamil Nadu, India

Acknowledgements The authors wish to thank the Avahan state implementation partners for their partnership in this study. The authors thank Dr Stephen Schensul, Dr Niranjan Saggurti and Dr Bidhu Bhushan Mahapatra for providing critical inputs during concept development and analysis. The authors also extend their gratitude to Dr Steve Mills from FHI 360, Asia Pacific Regional Office, Bangkok, Thailand, for his inputs in the finalisation of this manuscript. Finally, the authors thank the respondents for their participation in the study. An earlier version (abstract) of this research paper was presented at the STI \& AIDS World Congress 2013 in Vienna, Austria.

Contributors SR and KN contributed to concept development, data analysis and interpretation, and writing and finalisation of the manuscript. LR, PG, DY, $\mathrm{SS}, \mathrm{BG}, \mathrm{HR}, \mathrm{TS}$ and RSP contributed to concept design, review and finalisation of the manuscript.

Funding The Bill \& Melinda Gates Foundation funded this research through Avahan: the India AIDS Initiative.

Competing interests None.

Ethics approval Clearance for the study was taken from ethics committees of the participating institutes of Indian Council of Medical Research (National AIDS Research Institute, Pune; National Institute of Nutrition, Hyderabad; and National Institute of Epidemiology, Chennai) and FHI 360 (Protection of Human Subjects Committee).

Provenance and peer review Not commissioned; externally peer reviewed.

Data sharing statement IBBA Round 1 (2005-2007) and Round 2 (20092010) data are available on request from the National AIDS Research Institute
(NARI). The request form can be accessed from: http://www.nari-icmr.res.in/ pdf/IBBA/Agreement-for-accessing-raw-IBBA\%20_R1-\&-R2_data.pdf. Other IBBA-related documents are available at: http://www.ibbainfo.in.

Open Access This is an Open Access article distributed in accordance with the Creative Commons Attribution Non Commercial (CC BY-NC 4.0) license, which permits others to distribute, remix, adapt, build upon this work noncommercially, and license their derivative works on different terms, provided the original work is properly cited and the use is non-commercial. See: http:// creativecommons.org/licenses/by-nc/4.0/

\section{REFERENCES}

1. National AIDS Control Organisation MoHFW, Government of India. New Delhi, National Behavioural Surveillance Survey (BSS)-Female Sex Workers (FSWs) and their Clients, 2006.

2. Subramanian T, Gupte MD, Paranjape RS, et al. HIV sexually transmitted infections and sexual behaviour of male clients of female sex workers in Andhra Pradesh, Tamil Nadu and Maharashtra, India: results of a cross-sectional survey. AIDS 2008;22:S69-79.

3. McBride KR, Fortenberry JD. Heterosexual anal sexuality and anal sex behaviors: a review. J Sex Res 2010;47:123-36.

4. Voeller B. AIDS and heterosexual anal intercourse. Arch Sex Behav 1991;20:233-76.

5. Suryawanshi D, Bhatnagar T, Deshpande S, et al. Diversity among clients of female sex workers in India: comparing risk profiles and intervention impact by site of solicitation. Implications for the vulnerability of less visible female sex workers. PLoS ONE 2013;8:e73470.

6. National AIDS Control Organisation MoHaFW, Government of India. HIV Sentinel Surveillance 2010-11: A Technical Brief. New Delhi, 2012.

7. Samet JH, Pace CA, Cheng DM, et al. Alcohol use and sex risk behaviors among HIV-infected female sex workers (FSWs) and HIVinfected male clients of FSWs in India. AIDS Behav 2010;14:S74-83.

8. Baldwin JI, Baldwin JD. Heterosexual anal intercourse: an understudied, high-risk sexual behavior. Arch Sex Behav 2000;29:357-73.

9. Halperin DT. Heterosexual anal intercourse: prevalence, cultural factors, and HIV infection and other health risks, Part I. AIDS Patient Care STDS 1999;13:717-30.

10. Bradley J, Rajaram S, Moses S, et al. Female sex worker client behaviors lead to condom breakage: a prospective telephone-based survey in Bangalore, South India. AIDS Behav 2013;17:559-67.

11. Priddy FH, Wakasiaka S, Hoang TD, et al. Anal sex, vaginal practices, and HIV incidence in female sex workers in urban Kenya: implications for the development of intravaginal HIV prevention methods. AIDS Res Hum Retroviruses 2011;27:1067-72.

12. Bradley J, Rajaram S, Alary M, et al. Determinants of condom breakage among female sex workers in Karnataka, India. BMC Public Health 2011;11(Suppl 6):S14.

13. Beattie TS, Bradley JE, Vanta UD, et al. Vulnerability re-assessed: the changing face of sex work in Guntur district, Andhra Pradesh. AIDS care 2013;25:378-84.

14. Tucker S, Krishna R, Prabhakar P, et al. Exploring dynamics of anal sex among female sex workers in Andhra Pradesh. Indian J Sex Transm Dis 2012;33:9-15.

15. Schwandt M, Morris C, Ferguson A, et al. Anal and dry sex in commercial sex work, and relation to risk for sexually transmitted infections and HIV in Meru, Kenya. Sex Transm Infect 2006;82:392-6.

16. Heywood W, Smith AM. Anal sex practices in heterosexual and male homosexual populations: a review of population-based data. Sex Health 2012;9:517-26.

17. Veldhuijzen $\mathrm{NJ}$, Ingabire $\mathrm{C}$, Luchters $\mathrm{S}$, et al. Anal intercourse among female sex workers in East Africa is associated with other high-risk behaviours for HIV. Sex Health 2011;8:251-4.

18. Patra RK, Mahapatra B, Kovvali D, et al. Anal sex and associated HIV-related sexual risk factors among female sex workers in Andhra Pradesh, India. Sex Health 2012;9:430-7.

19. M. A. A Blind Spot in HIV prevention-Female Anal Sex.

20. Allen B, Cruz-Valdez A, Rivera-Rivera L, et al. [Affection, kisses, and condoms: the ABC of sexual practices of female sex workers in Mexico City]. Salud Publica Mex 2003;45(Supp 5):S594-607.

21. Decker MR, McCauley HL, Phuengsamran D, et al. Violence victimisation, sexual risk and sexually transmitted infection symptoms among female sex workers in Thailand. Sex Transm Infect 2010;86:236-40.

22. Saidel T, Adhikary R, Mainkar M, et al. Baseline integrated behavioural and biological assessment among most at-risk 
populations in six high-prevalence states of India: design and implementation challenges. AIDS 2008;22:S17-34.

23. Myers T, Rowe CJ, Tudiver FG, et al. HIV, substance use and related behaviour of gay and bisexual men: an examination of the talking sex project cohort. Br J Addict 1992;87:207-14.

24. Mimiaga MJ, Thomas B, Mayer KH, et al. Alcohol use and HIV sexual risk among MSM in Chennai, India. Int J STD AIDS 2011;22:121-5.

25. Greene E, Frye V, Mansergh G, et al. Correlates of unprotected vaginal or anal intercourse with women among substance-using men who have sex with men. AIDS Behav 2013;17:889-99.

26. Mahapatra B, Lowndes CM, Mohanty SK, et al. Factors associated with risky sexual practices among female sex workers in Karnataka, India. PloS ONE 2013;8:e62167.

27. Grov C, Wolff M, Smith MD, et al. Male clients of male escorts: satisfaction, sexual behavior, and demographic characteristics. J Sex Res 2014;51:827-37.

28. Alexander M, Mainkar M, Deshpande S, et al. Heterosexual anal sex among female sex workers in high HIV prevalence states of India: need for comprehensive intervention. PLOS ONE 2014;9:e88858.

29. Pitts MK, Smith AM, Grierson J, et al. Who pays for sex and why? An analysis of social and motivational factors associated with male clients of sex workers. Arch Sex Behav 2004;33:353-8.

30. Ramanathan S, Chakrapani V, Ramakrishnan L, et al. Consistent condom use with regular, paying, and casual male partners and associated factors among men who have sex with men in Tamil
Nadu, India: findings from an assessment of a large-scale HIV prevention program. BMC Public Health 2013;13:827.

31. Bandura A. Perceived self-efficacy in the exercise of control over AIDS infection. Eval Program Plann 1990;13:9-17.

32. Wulfert E, Wan CK. Condom use: a self-efficacy model. Health Psychol 1993;12:346-53.

33. Madhivanan P, Hernandez A, Gogate A et al. Alcohol use by men is a risk factor for the acquisition of sexually transmitted infections and human immunodeficiency virus from female sex workers in Mumbai, India. Sex Transm Dis 2005;32:685-90.

34. Schensul J, Singh SK, Gupta K, et al. Alcohol and HIV in India: a review of current research and intervention. AIDS Behav 2010;14:1-7.

35. Mimiaga MJ, Thomas B, Mayer KH, et al. Alcohol use and HIV sexual risk among MSM in Chennai, India. Int J STD AIDS 2011;22:121-5

36. Erickson PI, Bastani R, Maxwell AE, et al. Prevalence of anal sex among heterosexuals in California and its relationship to other AIDS risk behaviors. AIDS Educ Prev 1995;7:477-93.

37. Stulhofer A, Bacak V. Is anal sex a marker for sexual risk-taking? Results from a population-based study of young Croatian adults. Sex Health 2011;8:384-9.

38. Bharat S, Mahapatra B, Roy S, et al. Are female sex workers able to negotiate condom use with male clients? The case of mobile FSWs in four high HIV prevalence states of India. PLOS ONE 2013;8: e68043. 